UDK: 624.042.7

DOI: https://doi.org/10.24867/04CG05Ivanisevic

\title{
PROJEKAT VIŠESPRATNE AB ZGRADE SPRATNOSTI Po + Pr + 7, PREMA EVROPSKIM STANDARDIMA
}

\section{THE PROJECT OF DEPARTMENT STORE REINFORCED CONCRETE BUILDING ACCORDING TO EUROPEAN STANDARDS}

\author{
Miloš Ivanišević, Fakultet tehničkih nauka, Novi Sad
}

\section{Oblast - GRAĐEVINARSTVO}

Kratak sadržaj - U prvom dijelu rada prikazan je projekat armiranobetonske zgrade spratnosti $\mathrm{Po}+\mathrm{Pr}+7$, a $u$ drugom dijelu su upoređeni domaći (BAB '87) $i$ evropski (Evrokod) pravilnici po pitanju kontrole direktno oslonjenih ploča.

Ključne riječi: Armiranobetonska zgrada, Evropski standardi, Ploče direktno oslonjene na stubove

Abstract - The first part of the work consist the project of reinforced concrete building, basement + ground floor + 7 stories, and the second part consist flat slab (supported directly by columns) comparison of domestic (BAB '87) and European (Eurocod) regulations.

Key words: Reinforced concrete building, Eurocod, Flat slab supported directly by columns

\section{UVOD}

Rad obuhvata proračun AB zgrade prema evropskom standradu Evrokod. Korišćeni su softverski paketi Tower 6.0, ArmCad 2005 i AutoCad 2018. Teoretski dio rada bavi se fenomenom probijanja ploča direktno oslonjenih na stubove. Akcenat je postavljen na samoj kontroli probijanja istih i urađena je paralalena analiza, poređenje pravila Evrokoda i BAB '87.

\section{OPIS PROJEKTA}

\subsection{Projektni zadatak i arhitektosnko rešenje}

Prema projektnom zadataku potrebno je uraditi projekat armiranobetonske konstrukcije višespratne stambeno poslovne zgrade spratnosti dijelom $\mathrm{Po}+\mathrm{Pr}+7$ a drugim dijelom Po+Pr+6. Projektuje se prema Evrokod standardu. Lokacija objekta je Nevesinje, RS, BiH. Fundiranje objekta je predviđeno putem AB temeljne ploče. Dozvoljena nosivost tla je $300 \mathrm{kPa}$. Konstruktivni sistem objekta čine međusobno upravni ramovi. Unutrašnji stubovi i zidovi su na temeljnu ploču direktno oslonjeni. Arhitektonsko rešenje je predividjelo spratnu visinu podruma od $261 \mathrm{~cm}$, spratnu visinu prizemlja 370 $\mathrm{cm}$, dok je spratna visina ostalih etaža $289 \mathrm{~cm}$, izuzev poslednje gdje je $230 \mathrm{~cm}$. Za vertikalnu komunikaciju u objektu predviđa se stepenište i lift. U prizemlju se nalazi poslovni prostor. Tipske etaže su stambeni prostor i svaka se sastoji od pet stambenih jedinica.

\section{NAPOMENA:}

Ovaj rad proistekao je iz master rada čiji mentor je bio dr Đorđe Lađinović, red.prof.

\subsection{Konstruktivni sistem zgrade}

U konstruktivnom smislu objekat je ukrućeni skelet. Rasponi greda su različiti, pri čemu je najveći raspon 6.4 $\mathrm{m}$ pri čemu je poprečni presjek svih greda $20 / 40 \mathrm{~cm}$, izuzev onih u nivou prizemlja gdje su dimenzija 25/40 $\mathrm{cm}$. Stubovi su različitih dimenzija i to: 50/20, 70/20, 60/20 i 40/20 cm, pri čemu je svaka dimenzija svakog stuba u nivou podruma veća za $5 \mathrm{~cm}$ u odnosu na ostale etaže.

Međuspratna konstrukcija je projektovana kao sistem kontinualnih krstasto-armiranih ploča u oba pravca, debljine $d=14 \mathrm{~cm}$. Ploča krova (VIII-etaža) je debljine $d$ $=12 \mathrm{~cm}$.

Zidovi za ukrućenje su orijentisani u dva međusobno upravna pravca i debljine su $\mathrm{d}=20 \mathrm{~cm}$, izuzev dijela između temeljne i ploče prizemlja gdje je debljina svih zidova $25 \mathrm{~cm}$.

Stepenište je formirano kao dvokrako, koje se sastoji od dvije kose ploče (krakovi) i ploče međupodesta, izuzev stepeništa u podrumu koje se projektuje kao jednokrako. Debljina svih ploča stepeništa je $d=14 \mathrm{~cm}$. Stepenište je pozicionirano između dva $\mathrm{AB}$ zidna platna. Ploča međupodesta je oslonjena na $\mathrm{AB}$ gredu (jednom ivicom) $\mathrm{i}$ na $\mathrm{AB}$ platna (dvije naspramne ivice). Kose ploče se oslanjaju na međuspratnu tavanicu i na ploču podesta. Širina stepenišnog kraka iznosi $B=120 \mathrm{~cm}$, dok širina međupodesta iznosi $\mathrm{B}=130 \mathrm{~cm}$. Dimenzija stepenika $\mathrm{u}$ podrumu su $\mathrm{b} / \mathrm{h}=28 / 17 \mathrm{~cm}$, dok su na svim ostalim etažama $\mathrm{b} / \mathrm{h}=30 / 17 \mathrm{~cm}$.

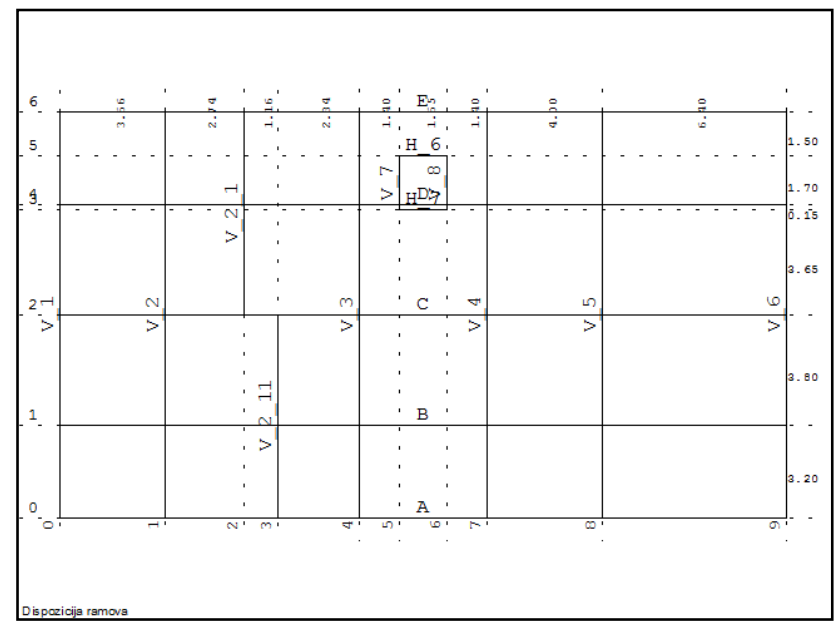

. Slika 1. Dispozicija ramova 
Fundiranje objekta je urađeno na temeljnoj ploči debljine $\mathrm{d}=40 \mathrm{~cm}$. Na istu direktno su oslonjeni svi stubovi i zidovi. Ispod temeljne ploče nasipaju se redom šljunak $(\mathrm{d}$ $=20 \mathrm{~cm})$, podložni beton $(\mathrm{d}=8 \mathrm{~cm})$ i zaštitni beton $(\mathrm{d}=5$ $\mathrm{cm}$ ) za hidroizolaciju koja se nalazi između podložnog i zaštitnog betona.

Fasadni zidovi u podrumu su armirano betonski i služe za prihvatanje pritiska tla u stanju mirovanja. Takođe, ovi zidovi dodatno ukrućuju objekat i debljine su $\mathrm{d}=25 \mathrm{~cm}$. $\mathrm{Na}$ njihovom spoljašnjem dijelu postavlja se sloj hidroizolacije.

Klasa betona svih AB elemenata glavnog nosivog konstruktivnog sistema je C30/37, dok je kvalitet armature svih elemenata B500C.

Dozvoljeni napon u tlu iznosi $300 \mathrm{kPa}$.

\subsection{Analiza opterećenja}

Prilikom projektovanja i analiziranja opterećenja vođeno je računa o svim relevantnim opterećenjima koja mogu da 'napadnu' konstrukciju u toku eksploatacionog vijeka. Opterećenja koja djeluju na objekat su podijeljena na sledeće grupe:

- Stalno opterećenje

- Korisna opterećenja

- Opterećenje od snijega

- Opterećenje od vjetra

- Seizmička opterećenja

Stalno opterećenje je ono koje potiče od sopstvene težine svih konstruktivnih (automatski generisano u softveru) i nekonstruktivnih (dodatno stalno) dijelova objekta.

Korisno opterećenje je ono koje proizilazi iz same namjene objekta tj. iz namjene pojedinih dijelova objekta. Ovo opterećenje je definisano standardom Evrokod 1 EN 1991-1-1:2002, a na osnovu kategorije upotrebe prostorije u stambenim, društvenim, trgovačkim i administrativnim zgradama.

Opterećenje snijegom se računa prema evropskom standradu EN 1991-1-3:2003 za krovove nagiba između $0^{\circ}$ i $30^{\circ}$ i aplicira se na konstrukciju u vidu jednopodijeljenog površinskog opterećenja.

Opterećenje vjetrom se računa prema Evrokod standardu EN 1991-1-4:2005 i nanosi se na konstrukciju kao površinsko nakon čega se konvertuje u linijsko.

Seizmičko opterećenje se izračunava pomoću softvera Tower 6.0 u kome je programiran seizmički proračun i nudi nam opciju seizmičkog proračuna prema Evrokod standardu EN 1998-1:2004 primjenom multimodalne spektralne analize. Ulazni podaci za proračun seizmičkog opterećenja kojima se raspolaže su sledeći:

1. Objekat se nalazi na tlu $\mathrm{C}$ kategorije;

2. Odnos a/ag jednak je 0,2 ;

3. Koeficijent prigušenja jednak je 0,05 .

\subsection{Modeliranje konstrukcije}

Objekat je prostorno modeliran u softverskom paketu Tower 6. Prilikom modeliranja vođeno je računa o postizanju jednostavnosti modela $i$ o što realnijem predstavljanju konstrukcije. Elementima su se zadate mehaničke i geometrijske karakteristike koje najbliže opisuju stvarnu konstrukciju.
Međuspratne tavanice su definisane kao pune armiranobetonske ploče. Odlikuju se apsolutnom krutošću u svojoj ravni, što kao posljedicu ima izjednačena pomjeranja svih vertikalnih elemenata u nivou tavanice. Pod armiranobetonskim pločama podrazumijevaju se ravni površinski nosači male debljine $u$ odnosu na ostale dvije dimenzije, a dominantno opterećenje na svoju ravan - savijanje. Definisane su kao tanke ploče kod kojih se uticaj transverzalnih sila može zanemariti. Usvojena debljina svih međuspratnih tavanica je $\mathrm{d}=14 \mathrm{~cm}$. Prilikom proračuna površinski element ploče se zamjenjuje mrežom konačnih elemenata zadate veličine $0,5 \mathrm{~m}$, pri čemu softver automatski generiše mrežu konačnih elemenata. Za temeljnu konstrukciju usvojena je temeljna ploča debljine $\mathrm{d}=40 \mathrm{~cm}$. Ovaj način temeljenja ima prednost jer se maksimizira kontaktna površina između objekta i tla, i samim tim smanjuje naprezanje tla. Oblik ploče definisan je oblikom osnove objekta, pri čemu je temeljna konstrukcija veća za $27,5 \mathrm{~cm}$ na svaku od spoljašnje ivice fasadnih zidova. Definisana je kao debela ploča što znači da se uzimaju u obzir i uticaji transverzalnih sila. Unutrašnji zidovi i stubovi su direktno oslonjeni na temeljnu ploču. Temeljnoj ploči su putem marke betona pridružene mehaničke karakteristike.

Ramovske konstrukcije su formirane u poprečnom i podužnom pravcu. Čine ih stubovi, grede, AB zidovi. Stubovi su različitih dimenzija a svaki stub $\mathrm{u}$ nivou podruma proširen je po $5 \mathrm{~cm}$ po svakoj stranici poprečnog presjeka. Prilikom modeliranja stubova redukovana je savojna krutost istih na 50\%. Grede su dimenzija 20/40 $\mathrm{cm}$, izuzev u nivou podruma gdje je dimenzija greda, zarad jednostavnosti izvođenja a diktirano od strane širine zidova, jednaka $25 / 40 \mathrm{~cm}$. Prilikom modeliranja greda redukovana je savojna krutost istih na $50 \%$, a torziona na $10 \%$. I stubovi i grede su modelirani kao linijski elementi. AB zidovi za ukrućenje su modelirani kao površinski elementi debljine $\mathrm{d}=20 \mathrm{~cm}$, izuzev u nivou podruma gdje je debljina i AB seizmičkih zidova i obodnih AB zidova d $=25 \mathrm{~cm}$. Zidovima za ukrućenje redukovana je savojna krutost na $50 \%$.

Stepenište je modelirano kao površinski element koji se sastoji od ploča: podesta i kosih ploča. Takođe modelirano je kao dvokrako u sklopu prostornog modela konstrukcije. Ploča međupodesta je oslonjena na $\mathrm{AB}$ gredu po jednoj dužoj ivici i na $A B$ zidove po dvije kraće ivice. Debljina svih ploča stepeništa je $\mathrm{d}=14 \mathrm{~cm}$.

Trodimenzionalni model objekta prikazan je na Slici 2.

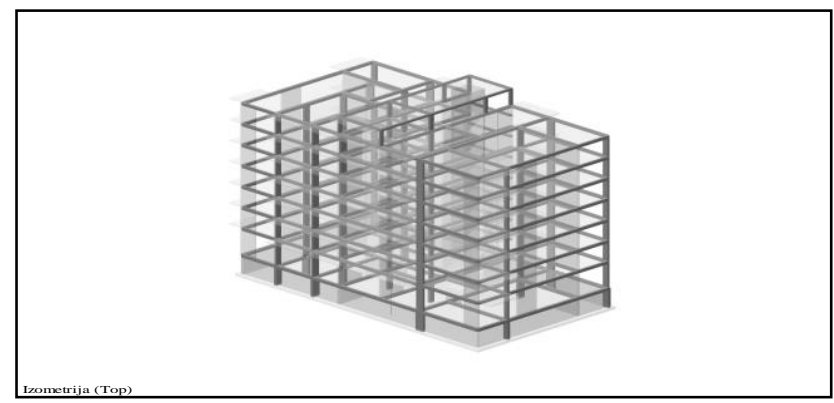

Slika 2.Trodimenzionalni prikaz modela

\subsection{Proračunske kontrole}

Urađene su sledeće kontrole koje su predviđene pravilnikom: 
1. Kontrola napona u tlu;

2. Kontrola normalizovane vrijednosti aksijalnih sila u stubovima;

3. Kontrola normalizovane vrijednosti aksijalnih sila u zidovima;

4. Kontrola relativnog spratnog pomjeranja;

5. Kontrola na probijanje temeljne ploče.

Konstrukcija je zadovoljila propisane uslove, osim kontrole na probijanje, gdje je bilo potrebno usvojiti dodatnu aramturu za osiguranje probijanja.

\subsection{Dimenzionisanje i armiranje elemenata}

Primjenom softverskog paketa Tower 6.0 izvršeno je dimenzionisanje karakterističnih ploča: krovne, tipskog sprata, prizemlja i temeljne ploče. Korišćena je kompletna šema opterećenja a softver automatski bira mjerodavnu kombinaciju u kojoj su uticaji najnepovoljniji i potreba za armaturom najveća. Dimenzionisanje i armiranje je izvedeno prema pravilniku Evrokod. Ploče prenose opterećenje $\mathrm{u}$ dva pravca, te su $\mathrm{s}$ toga armirane proračunskom armaturom u dva pravca. Težište gornje i donje armature svih ploča usvojeno je na a $=4 \mathrm{~cm}$, osim kod temeljne ploče gdje je a $=5,5 \mathrm{~cm}$. Izvršeno je i dimenzionisanje svih elemenata za dva karakteristična rama, jedan u X (Ram C) i jedan u Y (Ram 4) pravcu. Osim svih stubova i greda, izvršeno je i dimenzionisanje seizmičkih platna, koja se nalazi u sklopu predmetnih ramova. Za sve elemente predviđena je marka betona C30/37, a armirani su rebrastom armaturom B500C.

\section{POREĐENJE DOMAĆIH I EVROPSKIH PRAVILNIKA PO PITANJU KONTROLE PROBIJANJA PEČURKASTIH I DIREKTNO OSLONJENIH PLOČA}

\subsection{Uvod}

U opštem slučaju problem se javlja kada je ploča opterećena teretom velikog intenziteta na maloj površini, i/ili kada je oslonjena na stub male površine. Ovdje je razmatran problem konkretno vezan za zgradarstvo. Lom probojem se dešava uslijed prekoračenja napona smicanja u ploči i to po koničnoj ili piramidalnoj površi a najčešće po površi koja je između konične i piramidalne. Dodatni problem je $\mathrm{i}$ činjenica da je praksa pokazala značajna odstupanja od idealizovanih (koničnih ili piramidalnih) površi prilikom loma. Opšti princip kontrole i eventualnog osiguranja ploča od probijanja je proračun smičućeg napona $u$ referentnom presjeku/presjecima i upoređivanje istog sa referentnim naponima pri čemu su moguće 3 situacije:

- Betonski presjek (beton + armatura za savijanjepodužna) može da primi uticaje smicanja izazvane poprečnim opterećenjem i nije potrebna dodatna armatura (poprečna) za prihvat napona smicanja

- Betonski presjek (beton + armatura za savijanjepodužna) ne može da primi uticaje smicanja izazvane poprečnim opterećenjem i potrebna je dodatna armatura za prihvat napona smicanja

- Nivo smičućeg napona je takav da, mora biti korigovan betonski presjek (dimenzije i/ili kvalitet betona), iz razloga prekoračenja nivoa pritiska $\mathrm{u}$ kosim (betonskih) štapovima.

\subsection{Kontrola i osiguranje probijanja}

Prema domaćem pravilniku proračunska kontrola je bazirana na teoriji dopuštenih napona, što implicira da se razmatraju eksploatacioni uticaji. Nasuprot, prema Evrokod standardu, kontrola napona na smicanje određuje se primjenom teorije graničnih stanja.

BAB '87 definiše da bez obzira na poprečni presjek stuba, smičuća površ ima konični oblik, dok se dodatno ista, radi jendostavnosti proračuna, aproksimira kao cilindrična (Slika 3). Napon se kontroliše u kritičnom presjeku čiji je položaj prikazan na Slici 3.

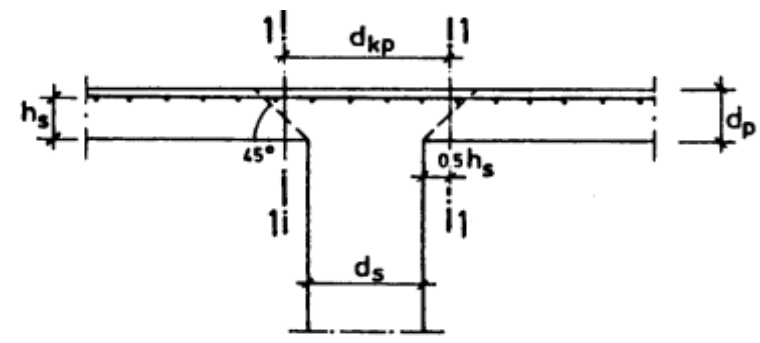

Slika 3.Kritičan presjek stuba poprečnog presjeka $d_{s}$ prema $B A B$ ' 87

U slučaju pravougaonog poprečnog presjeka stuba $(b / d)$ uvodi se (BAB '87) ekvivalentni kružni presjek.

Po Evrokodu potrebno je provjeriti napon pri smicanju na ivici stuba i na kontrolnom obimu $u_{l}$ a ukoliko je potrebna armatura za osiguranje proboja u kontrolnom presjeku $u_{l}$ potrebno je odrediti i naredni obim $u_{\text {out ef }} \mathrm{u}$ kome ista nije potrebna (Slika 4.)

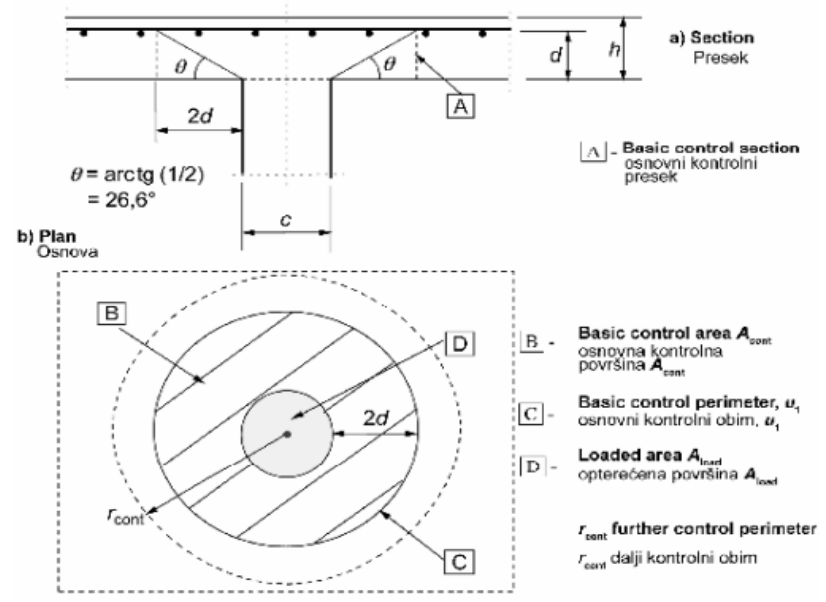

Slika 4. Položaj osnovnog i spoljašnjeg kontrolnog obima prema Evrokodu

Evrokod, za razliku od BAB '87, prilikom proračuna uzima u obzir i oblik poprečnog presjeka stuba i to na način prikazan na Slici 5.
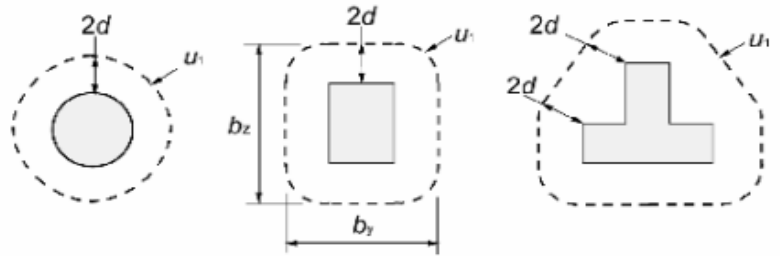

Slika 5. Tipični osnovni kontrolni obim oko stubova različitih poprečnih presjeka (Evrokod) 
Domaći pravilnik u potpunosti ignoriše činjenicu mogućeg ekcentriciteta normalne sile unutrušnjih stubova, dok istu činjenicu Evrokod uvažava i uvodi u proračun. BAB '87 određuje potrebu za armaturom na osnovu 75\% posto ukupne sile probijanja. Na ovaj način se grubo uvažava doprinos betona u prijemu napona smicanja. I Evrokod predviđa da se ukupna nosivost $v_{R d, c s}$ (beton+arm. savijanja+arm. smicanja) računa kao 75\% $v_{R d, c}$ (beton + armatura za savijanje) i nosivost armature za obezbjeđenje probijanja. Ukupna armatura za osiguranje proboja treba da se rasporedi na rastojanju $k * d(k-$ preporučena vrijednost je $1,5, d$ - srednja statička visina dva međusobno upravna pravca) unutar posmatranog kontrolnog obima.

\subsection{Primjer}

Razlike između predmetih pravilnika su najlakše uočljive na sledećem primjeru:

\begin{tabular}{|l|c|c|}
\hline & BAB '87 & Evrokod \\
\hline Prečnik stuba & $d s=30 \mathrm{~cm}$ & $c=30 \mathrm{~cm}$ \\
\hline Statička visina ploče & $h_{s}=35 \mathrm{~cm}$ & $d_{s}=35 \mathrm{~cm}$ \\
\hline$\mu_{\text {sr }}$ & $0,5 \%$ & $0,5 \%$ \\
\hline Kvalitet betona & $M B 40$ & $C 30 / 37$ \\
\hline Kvalitet armature & $M A 500 / 560$ & $B 500 C$ \\
\hline Normalna sila & $N_{g}=500 \mathrm{kN} ;$ & $N_{g}=500 \mathrm{kN} ;$ \\
& $N_{p}=400 \mathrm{kN}$ & $N_{p}=400 \mathrm{kN}$ \\
\hline Moment savijanja & $M_{v}=40 \mathrm{kNm}$ & $M_{v}=40 \mathrm{kNm}$ \\
\hline
\end{tabular}

Rezultati:

\begin{tabular}{|l|c|c|c|c|}
\hline & $\begin{array}{c}\text { BAB '87- } \\
\text { centrična } \\
\text { aksijalna } \\
\text { sila }\end{array}$ & $\begin{array}{c}\text { BAB '87- } \\
\text { ekscentričn } \\
\text { a aksijalna } \\
\text { sila }\end{array}$ & $\begin{array}{c}\text { Evrokod- } \\
\text { proračunsk } \\
\text { e } \\
\text { vrijednosti }\end{array}$ & $\begin{array}{c}\text { Evrokod- } \\
\text { karakteristi } \\
\text { čne } \\
\text { vrijednosti }\end{array}$ \\
\hline $\begin{array}{l}\text { Kontrol } \\
\text { ni obim }\end{array}$ & $\begin{array}{c}O_{k p}= \\
2,042 \mathrm{~m}\end{array}$ & $\begin{array}{c}O_{k p}= \\
2,042 \mathrm{~m}\end{array}$ & $\begin{array}{c}O_{o k p}= \\
5,341 \mathrm{~m}\end{array}$ & $\begin{array}{c}O_{o k p}= \\
5,341 \mathrm{~m}\end{array}$ \\
\hline $\begin{array}{l}\text { Smičući } \\
\text { napon }\end{array}$ & $\begin{array}{c}\tau=\mathbf{1 . 2 7} \\
\mathrm{mPa}\end{array}$ & $\begin{array}{c}\tau=\mathbf{1 . 4 9} \\
\mathrm{mPa}\end{array}$ & $\begin{array}{c}v_{E d}= \\
\mathbf{0 , 6 7} \mathrm{mPa}\end{array}$ & $\begin{array}{c}v_{E d}= \\
\mathbf{0 , 4 6} \mathrm{mPa}\end{array}$ \\
\hline $\begin{array}{l}\text { Max. } \\
\text { nosivost } \\
\text { b+as }\end{array}$ & $\begin{array}{c}\tau_{1}=0,94 \\
\mathrm{mPa}\end{array}$ & $\begin{array}{c}\tau_{1}=0,94 \\
\mathrm{mPa}\end{array}$ & $\begin{array}{c}v_{R d, c}= \\
0,52 \mathrm{mPa}\end{array}$ & $\begin{array}{c}v_{R d, c}= \\
0,36 \mathrm{mPa}\end{array}$ \\
\hline $\begin{array}{l}\text { Max. } \\
\text { nosivost } \\
\text { b+as+ap }\end{array}$ & $\begin{array}{c}\tau_{2}=1,34 \\
\mathrm{mPa}\end{array}$ & $\begin{array}{c}\tau_{2}=1,34 \\
\mathrm{mPa}\end{array}$ & $\begin{array}{c}v_{R d, m a x}= \\
5,28 \mathrm{mPa}\end{array}$ & $\begin{array}{c}v_{R d, m a x}= \\
3,64 \mathrm{mPa}\end{array}$ \\
\hline
\end{tabular}

\subsection{Zaključak}

- BAB '87 kontroliše napon samo u jednom presjeku, i samim tim predlaže osiguranje jednog presjeka (tačnije predlaže osiguranje od korijena stuba do kritičnog presjeka u zoni 1,5 $h_{s}$ ), ignorišući moguću situacija da je i u presjecima udaljenijim od kritičnog prekoračen maksimalni smičući napon nosivosti ploče bez armature za prihvatanje smicanja. Evrokod kontroliše sve presjeke od ivice opterećene površine do prvog obima gdje armatura nije potrebna.

- Evrokod uzima u obzir povećanje smičućeg napona uslijed ekscentričnosti normalne sile preko koeficijenta $\beta$, dok domaći pravilnik za ugaone i ivične stubove, pomenute efekte uzima u obzir grubo, povećanjem poprečne sile po jedinici dužine obima a za unutrašnje stubove ignoriše pomenute efekte.

- Sporna činjenica sa domaćim pravilnikom je i da se maksimalni dozvoljeni napon sa poprečnom armaturom kontroliše u kritičnom presjeku (određen nosivošću pritisnutog betona), dok evropski standard isti napon kontroliše uz samu ivicu stuba. Priroda problema je takva, da će maksimalni napon javiti uz samu ivicu stuba, pa je u skladu sa rečenim, i način kontrole prema Evrokodu preciziniji.

- BAB '87 kontrolu kod stubova pravougaonog poprečnog presjeka uvodi ekvivalentni kružni presjek. U sučaju odnosa stranica takvog presjeka većeg od 1,5 usvaja odnos $a / b=1,5$. Time se grubo, uvažava činjenica da se kod ovakvih opterećenih površina dešava koncentracija napona u 'uglovima' kontrolnog obima. Istina, ni u samom tekstu Evrokoda, ovaj problem nije analiziran detaljnije.

- Oba pravilnika ignorišu problem probijanja ploča ivičnim dijelovima zidnih elemenata (seizmička platna koja prenose velike momente savijanja), direktno oslonjenih na temeljnu ploču, kao i problem sporne aktivacije punog kontrolnog obima u situacijama kada dolazi do oslanjanja relativno tanke ploče na stub velikih dimenzija.

- Generalno, Evrokod realnije 'opisuje' probijanje punih AB ploča direktno oslonjenih na stubove.

\section{LITERATURA}

1. Evrokod 1: Dejstva na konstrukcije - deo 1-1: Zapreminske težine, sopstvena težina, korisna opterećenja na zgrade, Beograd 2009.

2. Evrokod 1: Dejstva na konstrukcije - deo 1-3: Dejstva snega, Beograd, 2009.

3. Evrokod 1: Dejstva na konstrukcije - deo 1-4: Dejstva vetra, Beograd, 2009.

4. Evrokod 2: Proračun betonskih konstrukcija - deo 1-1: Opšta pravila i pravila za zagrade

5. Beton i armirani beton '87 - 1 - Priručnik, Beograd, 1995.

6. Beton i armirani beton '87 - 2 - Prilozi, Beograd, 1995.

7. Dr. Zoran Brujić: „Betonske konstrukcije u zgradarstvu prema Evrokodu - materijal sa predavanja iz predmeta Betonske konstrukcije", Novi Sad, 2018.

8. Živorad Radosavljević, Dejan Bajić: „Armirani beton 3“- Građevinska knjiga, Beograd, 2008.

9. S. Stefanović: Fundiranje, Naučna knjiga, Beograd, 1989.

10. M. Čaušević: Dinamika konstrukcija, Tehnička knjiga, Zagreb, 2010.

\section{Kratka biografija:}

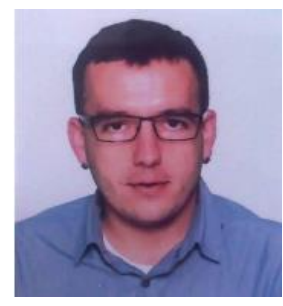

Miloš Ivanišević rođen je u Mostaru (Bosna i Hercegovina) 1992. godine. Master rad na Fakultetu tehničkih nauka iz oblasti Građevinarstva Seizmička analiza konstrukcija odbranio je 2019.god. 